Maria Virginia Borges Amaral

mvirginia39@gmail.com

raduada em Serviço Social (1977), mestre em Letras e Linguística (1994) e doutora em Letras e Linguística (1999) pela Universidade Federal de Alagoas (UFAL), onde atua como professora associada dos cursos de graduação e pós-graduação em Serviço Social e em Letras e Linguística.

\section{A negação da memória do trabalho no discurso do capital $^{1}$}

The denial of working memory in the capital's discourse

1

Agradecimento ao CNPq - Centro Nacional de Desenvolvimento Científico e Tecnológico - pelo apoio às pesquisas realizadas pela autora deste artigo.

\section{Abstract}

This article presents a discourse analysis of capital that intends to regulate, give a new meaning and silence the discursive memory of work. The sense of work historically settled in the discourses of the fundamental classes of this society is appropriated by institutional representatives of capital to be denied. New ideas are formulated from evaluative images that obscure the workers and prevent them from knowing their subject position, their real identity in labor relations, producing oblivion effects. This is what this paper aims to demonstrate.

Keywords: Work; Discourse; Discoursive Memory; History.

ria Discursiva; História. 

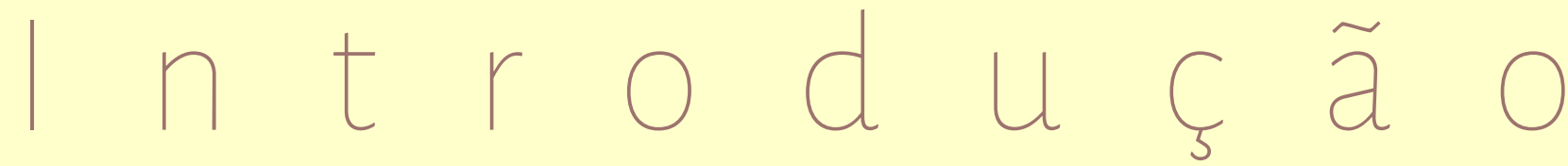

título deste artigo, antes de se conformar à negatividade, sugere que a reviravolta das ideias dominantes no campo discursivo do trabalho e as tentativas de negação da identidade desta ação humana são inerentes à lógica e ao controle do capital. As ideias sobre o trabalho hoje fazem parte de um universo discursivo onde são formuladas imagens valorativas que ofuscam os trabalhadores e os impedem de conhecer sua posição de sujeito, sua real identidade nas relações de trabalho, produzindo efeitos de desmemoriação. Esse é o ponto de partida da análise do discurso sobre o trabalho, formulado e divulgado nos domínios do capital, que apresentamos neste artigo.

Alguns conceitos fundamentais com os quais a Análise do Discurso trabaIha, sob os parâmetros teóricos que Ihe são específicos, serão recuperados aqui como orientadores da investiga- ção realizada. Para a exposição do que pretendemos demonstrar, dividimos o artigo em, basicamente, dois pontos articulados ao conteúdo da análise: fundamentos da teoria marxiana sobre o trabalho e a análise propriamente dita do discurso, objeto deste estudo, à luz de conceitos fundamentais da teoria do discurso.

\section{O domínio discursivo da memória}

Em uma reflexão sobre arquivo que resultou em um artigo publicado em 2014 (AMARAL, 2014), pensamos a relação arquivo e memória discursiva numa perspectiva de historicidade, o que nos levou ao conceito de memória revisto e definido para além da vinculação à faculdade de conservar, lembrar e evocar fatos de experiências vividas e tudo que estiver associado aos mesmos, inclusive 
os não presenciados, mas conhecidos por meios diversos de comunicação.

Consideramos a noção de memória associada à compreensão dos conceitos de arquivo e de história, uma relação indissociável em que se pode identificar a memória discursiva nessas particularidades conceituais. A memória discursiva posiciona-se no domínio discursivo de memória caracterizado pelo interdiscurso, um operador discursivo que permite a constituição e a funcionalidade de discursos transversos ${ }^{1}$. Reconhecemos, a partir de Courtine (2009), que o domínio de memória no discurso não aniquila a presença dos outros dois domínios (domínio de atualidade e o domínio de antecipação); na malha discursiva, todos contribuem para a produção de efeitos de sentido.

Decerto, é no domínio de memória que está a possibilidade de, no processo de conhecimento de discursos, o analista identificar um domínio das formulações-origem (não necessariamente "o começo" do processo discursivo, como sugere o termo) responsável pela

1 Assim como definido por Pêcheux (1988, p. 164): “'discursos transversos', que efetuam um encadeamento entre um discurso com o seu 'outro', o que não se mostra imediatamente na superfície discursiva”. constituição do lugar onde ocorrem os enunciados "que configuram como elementos de saber próprio a uma FD [Formação Discursiva]" (COURTINE, 2009, p. 112). Na teoria social crítica marxiana, como veremos adiante, encontra-se a formulação clássica de que "trabalho [ou força de trabalho] é mercadoria". Retomada por outras formulações marxistas ou posta à margem do processo de produção por outros discursos, é, por vezes, transformada, enquadrada, escondida, para ressurgir ressignificada na história do capitalismo. As formulações-origem, portanto, não podem ser consideradas enunciados passados ao qual se pode fazer meras remissões no presente.

Arquivo, memória e história são conceitos que encerram em si grandes paradoxos e ambiguidades, para usar uma consideração de Jacques Le Coff (2013) ao se referir à história. Ceralmente, pensa-se arquivo como lugar de "coisa velha", memória como lembranças do passado e história como ciência do passado; os três conceitos estariam, pois, ligados ao passado. Essa compreensão apaga a natureza do arquivo, a função da memória e a contradição 
da história, aniquila-se a dialética entre passado, presente e futuro; consequentemente "o presente é desmemoriado, apagando o sentido que os acontecimentos poderiam dar à vida" (AMARAL, 2014, p. 22).

Ora, o arquivo, numa perspectiva de historicidade, não implica uma representação do passado, nem uma representação do futuro, visto que a historicidade, segundo Jameson (1996, p. 290), é "uma percepção do presente como história". Decerto só há história no tempo presente, na contemporaneidade, como diz Le Coff (2013, p.53), "na medida em que o passado é apreendido no presente e responde, portanto, a seus interesses, o que não só é inevitável como legítimo"; e mais, "o interesse pelo passado está em esclarecer o presente" (LE COFF, 2013, p. 15).

No domínio discursivo, a memória adquire outros elementos que a possibilitam cumprir a função de articular passado e presente, operando no domínio de atualização discursiva. Isto ocorre em um funcionamento discursivo onde a memória aciona elementos operadores como a paráfrase para se fazer representar, para adquirir con- cretude com as palavras. Nesse sentido, cabe ouvir Achard (1999, p. 16): "A memória não restitui frases escutadas no passado, mas julgamentos de verossimilhança sobre o que é reconstituído pelas operações de paráfrase". Os fatos ocorridos são reconstituídos pelo discurso (dos mais diversos gêneros, da arte, da ciência, do senso comum), pelas operações parafrásticas, e à memória, funcionando no discurso, cabe conduzir o que é plausível, que se pode admitir como provável, por não contrariar a verdade. Quando se diz, "toda brincadeira tem um fundo de verdade", pode-se parafrasear com "toda mentira tem um fundo de verdade" visto que se julga a possibilidade de o dito aproximar-se de alguma verdade e, portanto, não ser de todo negativo, improvável. O julgamento é conduzido pelas propriedades discursivas que acionam a memória do dizer.

Por conseguinte, memória discursiva, nesta perspectiva teórica, revelando-se como interdiscurso, consiste em, como trata Orlandi (2002, p. 31), um "saber discursivo que torna possível todo dizer e que retorna sob forma do pré-construído, o já dito que está na base do 
dizível, sustentando cada tomada de palavra". A ação operativa da memória no discurso se dá, pois, por meio da paráfrase, o principal mecanismo discursivo em que se expressa o interdiscurso, conforme entende Guimarães (1995, p. 68): "aquilo que se significa, os efeitos de sentido, são efeitos do interdiscurso no acontecimento". Portanto, o aqui (lugar) e o agora (tempo) do discurso por si só não garantem os sentidos, tampouco o sujeito a quem é atribuída a responsabilidade do dizer. O discurso, ao ser anunciado, mobiliza um conjunto complexo de outros dizeres instalados, produzidos e reproduzidos pela memória discursiva. Então, a paráfrase é o operador da memória por excelência. Os efeitos de sentidos produzidos pelos e nos discursos são constituídos numa operação parafrástica. A noção de paráfrase discursiva que orienta as análises de discurso nesta perspectiva histórica é uma noção "contextual" porque depende das formações discursivas, do espaço de significação sócio-histórico aos quais o discurso está relacionado e onde podem produzir sentidos.

Desta feita, pode-se afirmar que o sentido não é exclusividade de uma palavra, ele é resultado de um con- junto complexo de dizeres, historicamente sedimentado e acionado com a colaboração da memória discursiva, operando em formações discursivas, lugares que acumulam práticas de discurso e definem o que pode e o que não pode ser reformulado daquilo que foi dito. Como diz Achard (1999, p. 15), "o passado, mesmo que realmente memorizado, só pode trabalhar mediando as formulações que permitem reenquadrá-lo no discurso concreto face ao qual nos encontramos". Disto decorre o processo de atualização caracterizado como domínio discursivo de atualidade. Em outras palavras, ao acionar o passado para produzir sentido no presente o discurso estabelece conexões de paráfrases capazes de reformulações adequadas aos propósitos do movimento discursivo atual. O passado só pode fazer sentido no presente se adaptado ao "novo" discurso, seja reafirmando-o, seja negando-o. Em qualquer direção a memória estará historicamente atuando e contribuindo para o conhecimento e fortalecimento da posição do sujeito na formação discursiva em que está inscrito o discurso que representa.

Os fatos de discurso, dos quais fala- 
remos neste artigo, inscrevem-se na memória discursiva do trabalho e produzem sentido na formação discursiva cuja extensão abrange o maior espaço discursivo da sociedade regida pelas leis do capital: o mercado - lugar de circulação e transação de mercadorias. É certo que este lugar é lido e interpretado por diversos pensadores dos mais diferentes domínios discursivos, desde os domínios da administração científica, passando pelos das práticas econômicas até os que lidam com a subjetividade dos trabalhadores para moldá-los aos interesses do capital. Evidentemente, as práticas discursivas que se ocupam de questões concernentes ao trabalho são exercidas em várias instâncias de natureza pública ou privada, por órgãos governamentais ou de iniciativa privada, empresariais ou populares, todos expõem em alguma medida suas propostas para minimizar os conflitos nas relações de trabalho.

Uma vez situada a perspectiva que define a relação entre arquivo, história e memória proponho, neste trabalho, mostrar o funcionamento da memória discursiva em um enunciado marcado pela modalidade negativa para produ- zir efeitos ideológicos de desmemoriação. Procurarei, mostrar essa ocorrência discursiva em um único enunciado da memória discursiva do trabalho inscrita na prática social do capitalismo contemporâneo. O enunciado foi extraído do discurso da Organização Internacional do Trabalho (OIT), porta-voz do sujeito universal - o capitalismo - e, por isso, representante dos três segmentos pilares da sociedade capitalista: governantes, empresários e trabalhadores.

\section{Sobre o discurso em análise}

O organismo internacional que trata sobre o trabalho, cujo discurso tomamos para análise - a Organização Internacional do Trabalho (OIT) -, apresenta-se como uma agência especializada das Nações Unidas com a missão de promover oportunidades para que homens e mulheres possam ter acesso a um Trabalho Decente (OIT, [2012], 2015). É uma das maiores representantes corporativas do capitalismo no mundo, sendo, pois, um sujeito discursivo, porta-voz de formações discursivas originárias e re- 
presentantes do capital. Sua história está atrelada à história do desenvolvimento, das crises e dos avanços da sociedade capitalista, sobretudo nos períodos das Grandes Guerras Mundial. É, portanto, produto da história real, da luta de classes de uma época marcada pela destruição social, política e econômica decorrente daquele acontecimento. Foi fundada em 1919, justamente quando o mundo procurava se reerguer após os desastres econômicos, sociais, políticos e naturais causados pela Primeira Guerra Mundial (1913-1918). Tinha como proposta promover a "justiça social" para alcançar a "paz universal". A justiça social para a OIT está diretamente relacionada ao trabalho, às condições de trabalho e a qualidade de vida dos trabalhadores. A esta instituição foi delegada a responsabilidade de formular e aplicar as Normas Internacionais do Trabalho com o intuito de dirimir os conflitos entre as classes. Mantém-se a representação no Brasil desde a década de 1950, com programas e atividades comprometidos com os objetivos da Organização.

O discurso da OIT se expressa em documentos que norteiam as suas ações. A sua Constituição, por exemplo, é um texto em vigor desde a sua aprovação na $29^{\mathrm{a}}$ reunião da Conferência In- ternacional do Trabalho realizada em Montreal, em 1946, e tem como anexo a Declaração referente aos fins e objetivos da Organização aprovada na $26^{a}$ reunião da Conferência, na Filadélfia, em 1944. Esta Declaração inspirou a Carta das Nações Unidas (1946) e a Declaração Universal dos Direitos Humanos (1948). Nelas foi reafirmado o princípio de "justiça social" considerado pelas grandes corporações capitalistas como uma condição necessária à paz mundial. É nesse material discursivo, documentados e registrados como concretude dos arquivos, onde podem ser apreendidos os elementos da memória discursiva, em que são identificadas ideias orientadoras das ações da OIT até hoje: o trabalho como fonte de dignidade; o trabalho não é mercadoria; a pobreza é uma ameaça à prosperidade e "todos os seres humanos tem o direito de perseguir o seu bem estar material em condições de liberdade e dignidade, segurança econômica e igualdade de oportunidades" (OIT, [1944], 2015).

Evidentemente, esses enunciados sugerem quão complexas são as expressões do discurso afirmador das ideias do capitalismo com vistas à produção material e controle do trabalho. Destes enunciados destacamos o trabalho não 
é mercadoria para percebermos como a sua condição negativa domina o dizer na tentativa de regular a memória do trabalho e destituí-lo da história (da luta de classes).

\section{A retomada da memória do trabalho como mercadoria}

Procuraremos identificar no acontecimento discursivo como a negação provoca interrupções no percurso da memória discursiva com vistas à desregularização do que está historicamente sedimentado na memória social. Primeiramente, é necessário perguntar por que o discurso apropriado pela OIT nega o trabalho como mercadoria; qual o sentido de mercadoria que a desmereceria como um predicativo do trabalho. Evidentemente, a resposta encontra-se no discurso que desvenda os nexos da sociedade capitalista e mostra no processo de produção o caráter destrutivo do capital.

Na teoria marxiana, tem-se o trabalho, antes de tudo, como um processo em que o homem "com sua própria ação, impulsiona, regula e controla seu intercâm- bio com a natureza" (MARX, 1988, p. 202). Somente o homem é capaz de prever, planejar, atribuir sentido ao processo do trabalho, porque somente a ele cabe um "ato teleológico" (LUKÁCS, 1979), um ato exclusivo do indivíduo, único ser capaz de produzir ideias, de elaborar representações do mundo, de pensar e pôr finalidade às suas ações laborais. Marx (1988) concebe o trabalho em seus estudos na forma exclusivamente humana, portanto com as particularidades racionais que o distingue de outras formas ditas trabalho, como o trabalho dos animais ou o das máquinas.

É interessante ressaltar, para esta reflexão sobre a negação do trabalho, que nesse movimento contraditório, capital e trabalho produzem sua identidade sempre em relação ao outro. Não há capital sem trabalho, e somente nesta forma de produção o trabalho produz sentido em relação à dominação do capital. O trabalho se deixa silenciar pelo capital ao permitir a negação da propriedade que constitui a sua identidade, ser mercadoria. Dessa forma, o discurso do capital silencia o trabatho e o ressignifica, produzindo um efeito de desmemoriação. Ao tentar eliminar da memória discursiva a mercadoria como predicado do trabalho, o discurso simula 
restabelecer no trabalho a sua condição de propriedade interna, de ser a "forma exclusivamente humana" que foi expropriada do trabalhador. O trabalho que deveria preservar essas particularidades, visto que, como diz Marx (1988, p. 202), ele é "antes de tudo",

[...] o processo de que participam o homem e a natureza, processo em que o ser humano com sua própria ação, impulsiona, regula e controla seu intercâmbio material com a natureza. Defronta-se com a natureza como uma de suas forças. Põe em movimento as forças naturais do seu corpo, braços e pernas, cabeça e mãos, a fim de apropriar-se de recursos da natureza, imprimindo-lhes forma útil à vida humana.

trabalho se torna exterior ao trabaIhador devido à alienação na sociedade capitalista. Marx (1989, p. 162) fala do trabalho exteriorizado ou alienado no modo de produção capitalista: "O trabaIho é exterior ao trabalhador, quer dizer, não pertence a sua natureza [ao seu ser]; [...]. Por conseguinte, o trabalhador só se sente em si fora do trabalho, enquanto no trabalho se sente fora de si". É o objetivo do discurso do capital, acirrar o efeito de desmemoriação produzido no trabalho exteriorizado; o trabalhador "não se afirma no trabalho", esgota-se numa atividade prática de mortificação, e desloca suas necessidades vitais para "suas funções animais - comer, beber, procriar, quando muito na habitação, no adorno, etc. - enquanto nas funções humanas se vê reduzido a animal." O efeito de regulação ou "eliminação" da memória discursiva produzido nas ações de controle do capital sobre o trabalho. Ao capital convêm que o trabalho perca a sua memória discursiva-histórica, mesmo que seja de natureza destrutiva, para fortalecer a dominação. Interessa-lhe a força de trabalho humana como mercadoria, embora fetichizada no discurso do "trabalho decente" da OIT.

Mas a questão é mais complexa do que aparenta. Para o trabalho se tornar mercadoria "tem de ser empregado em valores de uso, em coisa que sirvam para satisfazer as necessidades de qualquer natureza" (MARX, 1988, p. 201). A complexidade do conceito de trabalho na concepção de Marx tem embasamento no de mercadoria, ponto de partida da sua investigação:

A mercadoria é, antes de mais nada, um objeto externo, uma coisa que, por suas propriedades, satisfaz necessidades humanas, seja qual for a natureza, a origem delas, provenham do estômago ou da fantasia. Não importa a maneira como a coisa satisfaz a necessidade humana, se diretamente, como meio de subsistência, objeto 
de consumo, ou indiretamente, como meio de produção (MARX, 1988, p. 41).

Deste conceito deduz-se que trabaIho também é mercadoria, o trabalho é meio de produção. Segundo Marx (1988, p. 45), a força de trabalho humana ou o trabalho humano, "constitui a substancia dos valores [...] que se revela nos valores do mundo das mercadorias". E mais: "qualquer mercadoria se troca por outra nas diversas proporções" (Idem, p. 43). Trabalho troca-se por dinheiro (mercadoria) em forma de salário. Portanto, nesta sociedade não se pode negar que trabalho é mercadoria.

Mesmo assim, o discurso da OIT retoma o discurso da economia política, acerca do trabalho na ótica da teoria social crítica marxiana, na tentativa de deslocar e desregular os sentidos produzidos neste outro lugar discursivo que contraria o seu. Quando o discurso afirmativo do capital intenta negar o trabalho dizendo que trabalho não é mercadoria intenciona desmascarar o discurso da crítica onde se diz que trabalho é mercadoria. A negação do trabalho como mercadoria formulada no discurso da OIT troca no presente ideias aparentemente do passado. Aqui lembramos Indursky (1990, p.121) quando diz que "O enunciado negativo refuta a que se lhe opõe ideologicamente". Um enunciado negativo remete ao dito que se quer silenciar; é uma tentativa de substituição do sentido; uma maneira de abafar o sentido censurado².

Cabe lembrar que as formas negativas dos discursos são expressões concretas do exercício das formações ideológicas compreendidas apenas em relação à prática social, elas são produtos da história real e nelas se mantêm e se reproduzem. As formações ideológicas que sustentam a prática social da sociedade capitalista (formação ideológica do capital e formação ideológica do trabalho) (AMARAL, 2007) conduzem um movimento constitutivo do silenciamento necessário, ou seja, o que não se deve dizer para se dizer o que é preciso ${ }^{3}$ em função da ordem vigente. As duas formações ideológicas fundamentais da ordem capitalista mantêm suas formas de representação, seus espaços de significaçõese seus discursos. Embora tenham particularidades que distinguem suas posições discursivas não são de todo autônomas e independentes, ambas se estabelecem em um processo de contradição em que

2 Orlandi (1992, p. 162-163) considera o silêncio "a possibilidade do dizer vir a ser outro". Para ela, usando a metáfora da "dobra", "o silêncio é o ponto de inversão possível [...] onde o discurso se desdobra em 'outras' palavras". 3 Análise inspirada em Orlandi (1992). 
se afirmam e se negam mutuamente. O capital e o trabalho formam um todo contraditório, se afirmam e se negam mutuamente numa relação de incompletude própria dessa relação dialética.

No decurso da história vê-se que as ideias do domínio do capital não medem esforços para silenciar as do campo do trabalho, seja por meio da repressão, seja por meio da persuasão, mas sempre lançando mão dos recursos discursivos-ideológicos que funcionam na luta de classes. Este é um dos aspectos do processo de dominação de uma classe sobre a outra, demonstrado por Marx e Engels (1986). Na sociedade dominada pelo capital, as ideias dominantes são as da classe dominante e, por isso mesmo, porser dominante, apropria-se das ideias dominadas e as adequa aos interesses da classe. "Os indivíduos que constituem a classe dominante possuem, entre outras coisas, também a consciência, e por isso pensam" (MARX \& ENCELS, 1986, p. 72). Na medida em que os indivíduos dominam enquanto classe, dominam como pensadores, regulam a produção e a distribuição de ideias que passam a ser dominantes em uma época histórica. Portanto, o ato discursivo de o capital negar o trabalho como mercadoria implica a ocultação das condições de exploração inerentes a este modo de produção. $\mathrm{O}$ trabalhador é conduzido a um processo de alienação muito mais potente; além de se desgastar física e mentalmente no trabalho como já acontece no processo de trabalho capitalista, tiram-lhe a capacidade de compreender a sua posição de sujeito dominado, expropriado, subsumido às condições impostas pelo capital.

Ao trabalhador é ocultada a subsunção formal do trabalho ao capital, como denominam Marx (2004, p. 94) quando se referem à forma que se funda na mais valia absoluta, constituída por atos essenciais: o primeiro é caracterizado pela relação monetária entre comprador - quem se apropria do sobretrabalho capitalista, e vendedor - quem fornece o sobretrabalho - o trabalhador. Nesse processo, "o comprador faz com que o vendedor caia sob a sua dependência econômica". O segundo ato, inerente ao anterior diz respeito às condições objetivas (meios de produção) e às subjetivas (meios de subsistência) do trabalho. Estas são monopolizadas pelo comprador e se lhe opõem como capital. "Quanto mais plenamente essas condições de trabalho se lhe põem como propriedade alheia, tanto mais plena e formalmente se estabelece a relação entre o capital e o trabalho assalariado" (Idem). No proces- 
so de produção da mais valia absoluta, o comprador impõe certas condições para o aumento da produção: aumenta o ritmo de trabalho, intensifica a vigilância sobre o processo de produção, ameaça com demissões caso a meta não seja alcançada, mesmo que para isto o trabaIhador perca sua saúde e seu bem-estar. A exigência é maior do que as compensações. Todo o excedente é recolhido em forma de lucro.

O discurso do capital nega o trabalho como mercadoria no processo de produção da mais valia absoluta onde opera a subsunção direta do processo de trabalho ao capital. Mas a negação atinge também a forma de subsunção real do trabalho no capital em que se produz mais valia relativa. Este processo está ligado ao avanço científico e tecnológico. Extraída toda a energia do trabalhador, esgotada sua capacidade humana de produzir mais valia absoluta, o capitalista investe em tecnologias para acelerar a produção e aumentar o lucro. O trabalhador é "convidado" a se retirar da cena produtiva sem nenhuma bonificação e em seu lugar trabalham as máquinas incrementadas pela tecnologia; a quantidade de trabalho humano é diminuída em função da força de trabalho mecânica.
Nesse ponto da produção capitalista, o trabalho desenvolve-se em grande escala graças à aplicação da ciência e da tecnologia, originando uma forma modificada da produção material que agora passa a constituir "a base para o desenvolvimento das relações capitalistas, cuja forma adequada corresponde, por consequência, a determinado grau de desenvolvimento alcançado pelas forças produtivas do trabalho" (Idem, p. 105). Por conseguinte, o capitalismo avança e conquista todos os ramos de produção, da indústria formal à artesanal, transforma a agricultura e o artesanato em grande indústria ou pequenas empresas formalmente capitalistas. O objetivo imediato da produção capitalista é produzir a maior quantidade possível de mais valia, e isto é alcançado com o desenvolvimento da subordinação real do trabalho ao capital.

A negação discursiva de que o trabalho é mercadoria tende a eliminar qualquer barreira que impeça a dominação da subjetividade do trabalhador pelo capital. Disto decorre que interessa ao capital que o produto do processo de trabalho contenha "o máximo possível de trabalho não pago, e isso só se alcança mediante a produção para a própria produção". Isto 
ocorre quando "as condições coletivas para o trabalho de numerosos operários que cooperam entre si, permitirem, enquanto tais, economizar" (Idem, p. 108), fazendo com que o valor relativo do produto decresça e aumente o valor absoluto. A subsunção real do trabalho ao capital equivale ao modo de produção capitalista na sua completude, é quando os capitalistas se apoderam totalmente do trabalho e se fortalecem. Mas, mesmo com a força que adquiriram, os capitalistas não podem anular as determinações gerais do processo de trabalho.

O trabalho continua a ser produtivo na medida em que se objetiva em mercadorias como unidade de valor de uso e de valor de troca. [...] É produtivo o trabalhador que executa um trabalho produtivo e é produtivo o trabalho que gera diretamente mais-valia, isto é que valoriza o capital (MARX, 2004, p. 109).

É importante ressaltar que o sentido de trabalho produtivo na teoria marxiana é relativo à produção de mais valia, de excedente que gera lucro para o capital no processo de produção de mercadoria. O que pareceria oposto ao trabaIho produtivo, o trabalho improdutivo não desvaloriza o trabalho em geral, ao contrário, acrescenta condições de realização e completude do modo de pro- dução capitalista na esfera dos serviços e da circulação das mercadorias.

\section{A negação da memória do trabalho}

Na concepção materialista do discurso compreende-se que um discurso tem nos seus nexos as ideias afirmativas reforçadas e as negativas reformuladas, constituindo a sua historicidade, a sua memória discursiva. Sendo a palavra a materialidade do discurso e a memória discursiva uma dialética da repetição e da regularização, conforme entende Pêcheux (1999, p. 52), é possível afirmar que a retomada de acontecimentos discursivos como este sobre o trabalho se dá por meio de mecanismos específicos como a paráfrase operada com a repetição para afirmar ou negar o discurso outro. Então, a palavra - materialidade discursiva - não se limita a retomar, na memória, às "mentalidades" de uma época, "mas as condições verbais dos objetos (científico, estético, ideológico...) em uma conjuntura histórica dada" (PÊCHEUX, 2011, p. 151-752).

Nessa linha de raciocínio, vemos a ne- 
gação polêmica e a denegação, a partir da discussão feita por Indursky (1990). Tomemos esses conceitos como operadores da memória discursiva. No enunciado trabalho não é mercadoria instaura-se uma negação polêmica porque representa posições de sujeitos de Formações Discursivas antagônicas, ocorrendo um confronto entre práticas discursivas sociais: uma historicamente constituída em defesa do capital e outra em oposição a sua lógica e a sua ação de exploração do trabalho. Ao refutar um saber discursivo da Formação Discursiva crítica refuta-se um saber aparentemente exterior à Formação Discursiva afirmativa que representa. $O$ elemento de saber refutado é trabalhoé mercadoria.

O sentido do enunciado negativo - trabalho não é mercadoria - só se estabelece em relação à memória discursiva, que autoriza o discurso transverso em que se inscreve o enunciado afirmativo - trabaIho é mercadoria - próprio ao discurso da crítica ao capital.

Ainda com base nas contribuições de Indursky, identificamos no enunciado em análise a ocorrência da denegação, também um mecanismo acionador da memória do discurso. Segundo Indursky (1990, p. 119), lembrando o conceito na psicanálise, "a denegação instaura-se quando o sujeito nega um comportamento seu que não reconhece, deixando-o recalcado em seu inconsciente". No campo da Análise do Discurso, Indursky considera denegação discursiva "aquela negação que incide sobre um elemento do saber próprio à FD que afeta o sujeito do discurso". Isso ocorre quando um elemento de saber que pode ser dito pelo sujeito no interior de uma mesma formação discursiva, mas mesmo assim é negado, permanecendo recalcado e se manifestando através da modalidade negativa. É o que acontece no enunciado trabalho não é mercadoria.

O confronto de posições do sujeito se estabelece no interior da mesma formação discursiva, na mesma que representa os interesses do capital. O enunciado que se encontra na memória discursiva desse dizer é a sua forma afirmativa trabaIho é mercadoria, ele também pertence à Formação Discursiva em que os sujeitos porta-vozes, representantes do discurso do capital, se inscrevem, e poderia ser dito, mas não o dizem por razões ideológicas, por colocar em risco os princípios da ideologia dominante.

No lugar discursivo em que os sujeitos são afetados transitam discursos pro- 
pagadores da formação ideológica do capital constituídas por um conjunto de ideias, princípios e procedimentos responsáveis pela reprodução do modo de produção capitalista. Nesse lugar, promulga-se um discurso de trabalho com dignidade, trabalho decente, que não poderia admitir formas diversas de exploração, em respeito aos princípios dos direitos humanos. Se o discurso deixasse transparecer que o trabalho é uma mercadoria, que no processo de produção material o trabalho assume forma de valor, contrariaria a máxima de respeito à pessoa e, sobretudo, à liberdade de "escolha do trabalho", conforme reza o Artigo $23^{\circ}$ da Carta Internacional dos Direitos do Homem (1948 [2001])4. Na Declaração da Filadélfia, de 1944 (OIT, 1944 [2015]), a memória discursiva deste artigo é retomada, reformulada e, numa operação parafrástica, preserva a essência do que se quer definir como trabalho nas sociedades capitalista: "atividade remunerada equitativa e satisfatoriamente, de sorte que permita ao

4 Carta Internacional dos Direitos do Homem (1948), Artigo 23. ${ }^{\circ}$ : "Toda a pessoa tem direito ao trabalho, à livre escolha do trabalho, a condições equitativas e satisfatórias de trabalho e à proteção contra o desemprego. 2. Todos têm direito, sem discriminação alguma, a salário igual por trabalho igual. 3. Quem trabalha tem direito a uma remuneração equitativa e satisfatória, que lhe permita e à sua família uma existência conforme com a dignidade humana, e completada, se possível, por todos os outros meios de proteção social". trabalhador reproduzir com dignidade a sua vida e a da sua família".

A história da sociedade capitalista dos dias atuais produz discursos com efeitos de deslizamentos da memória social constitutiva das relações sociais de dominação no trabalho que caracteriza a luta de classes. Hoje, a história se apresenta como vítima da memória do trabalho e faz um esforço para livrar-se dela. Formula discursos cujo teor é negar-se, negando a memória histórica. A história remaneja a memória para regularizar o seu campo atribuindo novos sentidos aos discursos já sedimentados. Procura emboscar em si o que é da sua própria constituição - o sentido de trabalho e a luta de classe.

\section{Considerações finais}

Deixemos aqui parte das nossas reflexões acerca da memória discursiva do trabalho e as investidas da ideologia dominante para regulá-la. Tudo nos conduziu a antigas certezas acerca da força do capitalismo para dominar o sujeito na sua totalidade, da sua força 
física aos seus pensamentos e à capacidade de elaborar ideias e julgamentos relativos à sua condição de vida.

Como diz Pêcheux (1997, p.157):

Se é verdade que a ideologia recruta sujeitos entre os indivíduos [...], é preciso, então, compreender de que modo os 'voluntários' são designados nesse recrutamento, isto é, no que nos diz respeito, de que modo todos os indivíduos recebem como evidente o sentido do que ouvem e dizem, lêem ou escrevem (do que eles querem e do que se quer the dizer), enquanto "sujeitos-falantes".

E mais adiante: "[...] sob a evidência de que 'eu sou realmente eu' [...] há o processo da interpelação-identificação que produz o sujeito no lugardeixado vazio" (PÊCHEUX, 1997, p. 159). Esse é o papel da ideologia dominante, criar para os sujeitos processos de identificação, seja negando o que está dado como certezas, com evidências aparentemente incontestáveis, seja regulando essas certezas, pondo-as em novos patamares e atribuindo novos valores (AMARAL, 2005).

O discurso da ideologia dominante na sociedade do capital em tempos atuais produz evidências de verdades inquestionáveis por meio de discursos aparentemente irrefutáveis. A Formação Discursiva defensora da ordem vigente define o que não pode ser dito para preservar a relação hierárquica na qual o poder é exercido e a exploração do homem pelo próprio homem é efetivada. Essa formação discursiva aciona o sistema de dispersão nas relações de trabalho, para estabelecer as regras a partir das orientações determinadas pelo capital em seu discurso atravessado pelos discursos de liberdade e igualdade para os trabalhadores, com isso negando a identidade real do trabalho-o trabalho é mercadoria.

Concluiremos estas reflexões com o pensamento marxiano, o qual aponta para o processo de interpelação-identificação do sujeito no espaço de significação do trabalho em que cada homem, sendo interpelado pela ideologia, vê no outro a sua imagem e com ele se identifica na ordem da desigualdade de classes - "eu sou realmente trabalhador" ou "eu sou realmente o patrão, dono do meu negócio": "Assim, na relação do trabalho alienado, cada homem olha os outros homens segundo o padrão e a relação em que ele próprio, enquanto trabalhador, se encontra" (MARX, 1989, p. 166).

No percurso analítico do discurso sobre o trabalho que ora apresentamos, tomamos por base a relação memória-história para aproximarmos o máximo possível 
do conhecimento acerca da condição humana no trabalho e da necessidade que a humanidade tem de sustentar-se em um imaginário capaz de reproduzir sua existência envolta de ilusões e sujeita aos efeitos de desmemoriação produzidos no discurso do capital. Embora tente, esse discurso não pode anular a identidade do trabalhador. Reconhecendo-se como sujeito explorado, o trabalhador poderá lutar; desconhecendo sua identidade, acomodar-se-á.

\section{Referências}

ACHARD, Pierre. Memória e reprodução discursiva do sentido. In: ACHAR, Pierre [et al]. Papel da memória. Campinas: Pontes, 1999. p. 11-22.

AMARAL, Maria Virgínia Borges. Discurso e Relações de Trabalho. Maceió: Edufal, 2005.

. OAvesso do Discurso-Análise de práticas discursivas no campo do trabalho. Maceió:

Edufal, 2007.

A dialética do arquivo: "pensar para trás", entender o presente e mudar o futuro. Conexão Letras, Porto Alegre, v. 9, n. 11, p. 11-22, 2014. ISSN 1980-332x. Disponível em: <http://seer.ufrgs.br/ index.php/conexaoletras/article/view/55138/33531>. Acesso em: maio 2016.

CARTA INTERNACIONAL DOS DIREITOS DO HOMEM (1948). Gabinete de Documentação e Direito Comparado Procuradoria-Ceral da República. Lisboa. 2001. Disponível em: $<$ http://unicrio.org. br/img/CartadaONU_Versolnternet.pdfs. Acesso em: jan. 2016.

CARTA DAS NAÇÕES UNIDAS E ESTATUTO DA CORTE INTERNACIONAL DA JUSTIÇA (1945). Disponível em: <http://unicrio.org.br/img/CartadaONU_Versolnternet.pdf>. Acesso em: jan. 2016.

COURTINE, Jean-Jacques. Análise do Discurso político: o discurso comunista endereçado aos cristãos. São Paulo: UFSCar, 2009.

GUIMARÃES, Eduardo. Os limites do sentido: um estudo histórico e enunciativo da linguagem. Campinas: Pontes, 1995.

INDURSKY, Freda. Polêmica e Denegação: Dois funcionamentos Discursivos da Negação. Cadernos de Estudos Linguísticos, Campinas, n. 19, p. 117-122, jul./dez. 1990.

JAMESON, Fredric. Pós-Modernismo-a lógica cultural do capitalismo tardio. São Paulo: Ática, 1996. 
LE GOFF, Jacques. História e memória. Campinas: Editora da Unicamp, 2013.

LUKÁCS, Georg. Ontologia do ser social, princípios ontológicos fundamentais de Marx. São Paulo: Ciências Humanas, 1979.

MARX, K; ENCELS, F. Aideologia alemã. São Paulo: Hucitec, 1986.

MARX, K. Trabalho assalariado e capital. (1850 [s/d]). In: Obras Escolhidas de Marxe Engels. São Paulo: Editora Alfa-Omega, 1984. v.1.

Ocapital. Tradução de Reginaldo Sant’ana. Rio de Janeiro: Bertrand Brasil, 1988. v.1.

Manuscritoseconômicos-filosóficos. Lisboa, Portugal: Edições 70, 1989.

Capítulo VI. Inédito de O Capital. São Paulo: Centauro, 2004.

ORLANDI, Eni Pulcinelli. As formas dosilêncio: no movimento dos sentidos. Campinas: Editora da Unicamp, 1992.

Análise do discurso: princípios e procedimentos. 4. ed. Campinas: Pontes, 2002.

ORGANIZAÇÃO DAS NAÇÕES UNIDAS PARA A EDUCAÇÃO, A CIÊNCIA E A CULTURA (UNESCO). Brasil. Declaração Universal dos Direitos Humanos garante igualdade social [1948]. 1998. Disponível em: <http://www.brasil.gov.br/cidadania-e-justica>. Acesso em: jan. 2016.

ORGANIZAÇÃO INTERNACIONAL DO TRABALHO. Constituição da organização internacional do trabalho(OIT) e seu anexo Declaração de Filadélfia [1944]. Setor de Embaixadas Norte, Lote 35, Brasília, DF, Brasil. Disponível em: <http://www.oit.org.br/sites/all/forced_labour/legis_jur/sumario>. Acesso em: 12 dez. 2015.

Organização Internacional do Trabalho Escritório no Brasil: trabalho decente para uma vida digna [2012]. Setor de Embaixadas Norte, Lote 35, Brasília, DF, Brasil. Disponível em: <www.oitbrasil. org.br>. Acesso em: 12 dez. 2015.

PÊCHEUX, Michel. Semântica e Discurso: uma crítica à afirmação do óbvio. Campinas: Editora da Unicamp, 1988.

. Ler o arquivo hoje. In: ORLANDI, E. (Org.). Cestos de Leitura: da história no discurso. Campinas: Editora da Unicamp, 1997. p. 55-66

Papel da memória. In: ACHARD, P. et al. Papel da memória. Campinas: Pontes, 1999.

Metáfora e Interdiscurso. In: PÊCHEUX, M. Análise de Discurso: Michel Pêcheux. Textos selecionados por Eni Puccinelli Orlandi. 2.ed. Campinas: Pontes; 2011. p. 151-161 